05

\title{
Проявление автоволн пластического течения в пресном льду при микроволновых измерениях
}

\author{
() Г.С. Бордонский, А.А. Гурулев \\ Институт природных ресурсов, экологии и криологии СО РАН, \\ Чита, Россия \\ E-mail: Igc255@mail.ru
}

Поступило в Редакцию 14 декабря 2018г.

В окончательной редакции 24 декабря 2018 г.

Принято к публикации 24 декабря 2018г.

Представлены результаты измерений коэффициента отражения микроволнового излучения от блока пресного льда, подвергающегося пластической деформации. Обнаружены сильные флуктуации фазы коэффициента отражения с экстремумом на длине волны электромагнитного излучения в среде $1.35 \mathrm{~cm}$. Эта длина волны соответствует области длин автоволн локализованного пластического течения в кристаллических средах.

DOI: 10.21883/PJTF.2019.06.47499.17645

В работах $[1,2]$ наблюдались аномалии микроволновых свойств льда при измерениях прохождения излучения в пресном льду как в лабораторных экспериментах, так и в натурных условиях. Одна из аномалий, обнаруженная на частотах $(f) 13-14 \mathrm{GHz}$, заключалась в искажениях поляризационных диаграмм интенсивности излучения, которые регистрировались с использованием 12 линейных поляризаций, повернутых относительно друг друга на $15^{\circ}$. При распространении монохроматического излучения в виде плоской электромагнитной волны в свободном пространстве и в однородной изотропной среде обнаруженные искажения не могли возникать. Для представления волн в этом случае достаточным является поляризационный базис, состоящий из двух ортогональных компонент.

В результате выполненных исследований был сделан вывод, что причиной аномалий является пластическая деформация (течение) поликристаллического льда. Было также установлено, что особенностью структуры исследуемого ледяного покрова, для которого обнаружены аномалии, оказалась преимущественная пространственная ориентация главной оптической оси кристаллов льда. Оси были ориентированы вертикально в основной части объема покрова. При этом для волн, вектор электрического поля которых был параллелен базисной плоскости кристаллов (т. е. перпендикулярен главной оптической оси), наблюдалось существенное уменьшение потерь мощности излучения при его распространении в среде. В специальном эксперименте была установлена неоднозначность первого параметра Стокса при измерениях в различных ортогональных поляризационных базисах при возникновении во льду пластической деформации, что также указывало на особый характер аномалии микроволновых свойств льда [2].

Обнаруженные электромагнитные явления невозможно было понять исходя из представлений об эффективной диэлектрической проницаемости среды, подвер- женной пластической деформации. Однако результаты работ [1,2] можно объяснить на основе новых представлений о процессах пластической деформации кристаллических сред, развитых в работах $[3,4]$. В них было показано, что деформации на макроуровне развиваются в виде волн локализованной пластичности. Эти волны представляют собой чередование областей пассивной кристаллической структуры и активной, в которой развивается пластическая деформация. Весьма интересным оказалось то, что значения длин волн локализованного пластического течения составляют приблизительно $1 \mathrm{~cm}$, а скорость их распространения $\sim 10^{-5}-10^{-6} \mathrm{~m} / \mathrm{s}[3,4]$.

Экспериментальные доказательства существования автоволн локализованного пластического течения немногочисленны. Например, в $[3,4]$ для выявления самопроизвольной стратификации использовалась методика двухэкспозиционной спекл-фотографии. Следует отметить, что исследование внутренней структуры непрозрачных образцов затруднено при использовании оптических методов.

Поскольку значения длин автоволн течения находятся в коротковолновой части сантиметрового диапазона, именно излучения с этими длинами волн могут наиболее эффективно использоваться для их регистрации и исследования. В таком случае можно ожидать сильных эффектов рассеяния волн любой природы. Если использовать для этой цели электромагнитное излучение, то необходимо выбрать кристаллическую среду, в которой наблюдается слабое затухание микроволнового излучения. Такой средой является пресный лед, в котором скин-слой в требуемом диапазоне достигает единиц и десятков метров [5]. Выбор частот для исследований определяется длинами автоволн течения. В $[3,4]$ предсказаны длины волн в интервале $0.5-2 \mathrm{~cm}$. Для электромагнитного излучения во льду с учетом действительной части относительной комплексной диэлектрической про- 


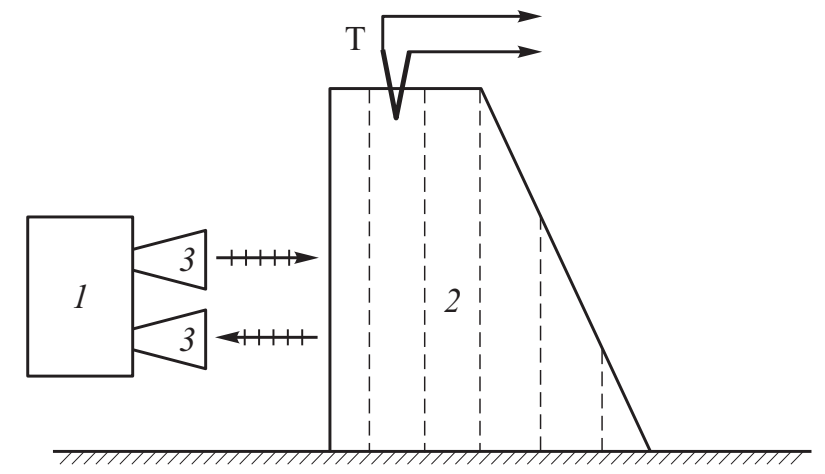

Рис. 1. Схема установки для измерений коэффициента отражения микроволнового излучения от блока пресного поликристаллического льда. 1 - векторный анализатор частотных характеристик, 2 - блок льда, 3 - рупорные антенны, Т термопара для измерения температуры льда. Штриховыми линиями в блоке отмечены базисные плоскости кристаллов льда. На лучах, исходящих и входящих в рупорные антенны, штрихами указаны направления векторов электрического поля волн.

ницаемости $\left(\varepsilon^{\prime}=3.15\right)$ интервал частот для таких же по значению длин волн составляет $8.8-20 \mathrm{GHz}$.

Цель настоящей работы - получить доказательство проявления автоволн течения в пресном льду и определить их характерные длины для данной среды. Для этого был выполнен лабораторный эксперимент с блоками льда, подвергающимися пластической деформации. Схема экспериментальной установки приведена на рис. 1.

В эксперименте измерялись параметры коэффициента отражения от блока льда, а именно фаза отраженного монохроматического излучения $(\varphi)$ и интенсивность отраженной волны $(I)$. Измерения выполнялись с использованием векторного анализатора частотных характеристик 1 фирмы „Микран“ Р4М-18 с автоматической записью выходного сигнала в компьютер. Пластическая деформация блока льда 2 создавалась путем его быстрого нагревания в воздушной среде. Для этого холодный блок льда с температурой $(T)-10^{\circ} \mathrm{C}$ помещался на стенд, находящийся в лабораторном помещении, с температурой воздуха $+20^{\circ} \mathrm{C}$. При этом была использована особенность механических свойств гексагональных кристаллов льда, которая заключается в их облегченной сдвиговой деформации вдоль базисных плоскостей [6]. Эта особенность позволяет проводить эксперименты со льдом при невысоких механических напряжениях без его разрушения при создании в среде градиента температуры, вызывающего пластическую деформацию.

Блоки льда для исследований изымались из ледяного покрова неглубоких пресных озер. Для этих объектов кристаллическая структура имеет преимущественное направление главной оптической оси кристаллов перпендикулярно поверхностям ледяного покрова. В таких образцах облегчена пластическая деформация вдоль базисных плоскостей, она достигается при возникновении градиентов температуры в среде. Размеры отдельных кристаллов составляли порядка $0.1-1 \mathrm{~cm}$. Блоки льда в виде усеченной пирамиды имели размеры в несколько десятков сантиметров. Грань блока 2, приближенная к векторному анализатору, была ориентирована перпендикулярно осям антенн, в то время как удаленная грань (рис. 1) имела наклон к этим осям. При такой геометрии образца исчезала интерференция между сигналами, отраженными от двух граней блока льда. Измерения выполнены на частотах $12-13.5 \mathrm{GHz}$, на которых ранее были обнаружены аномалии микроволновых характеристик льда $[1,2]$. Измерения проведены при сканировании в данном интервале частот, время одного сканирования составляло $5 \mathrm{~s}$. Температура образца измерялась термопарой, установленной на глубину от поверхности $\sim 1 \mathrm{~cm}$. В экспериментах измерялись изменение интенсивности и фаза отраженного излучения в зависимости от температуры и времени нагревания образца льда. При анализе результатов из массива данных выбрались результаты для 50 частот с интервалом между ними $0.1 \mathrm{GHz}$.

Выполненные исследования выявили частотную зависимость параметров отраженного от блока льда излучения. Результаты измерений для частоты $13 \mathrm{GHz}$, на которой были обнаружены выраженные аномалии характеристик отраженного сигнала, приведены на рис. $2, a, b$.

Были рассчитаны значения стандартного отклонения фазы $\left(S_{\varphi}\right)$ и интенсивности $\left(S_{I}\right)$ в зависимости от температуры льда в интервале $\sim 1^{\circ} \mathrm{C}$ (так как температура изменялась во времени). Частотный ход этих величин для различных температур от -5 до $-2^{\circ} \mathrm{C}$ представлен на рис. 3 .

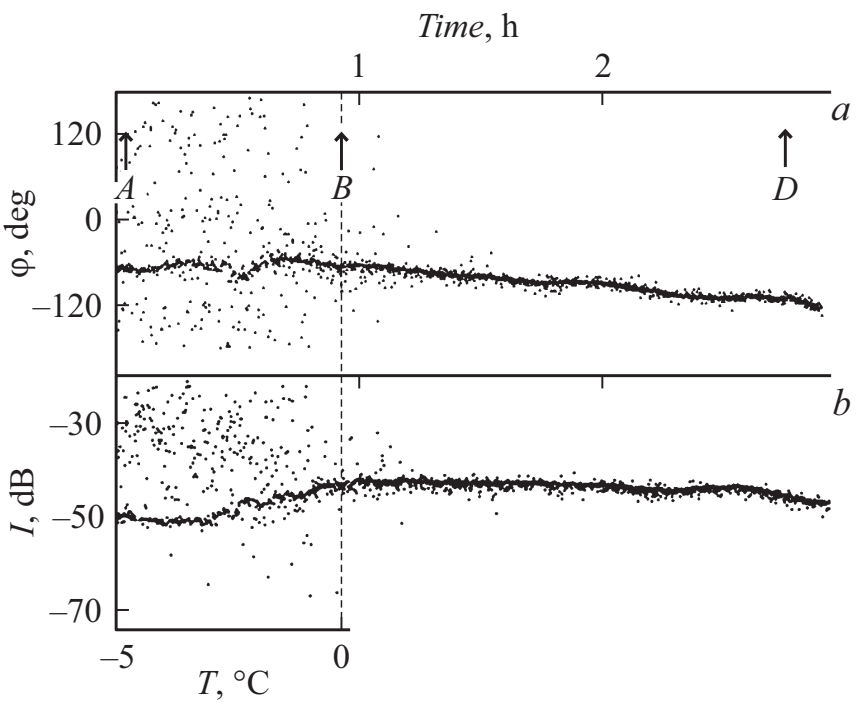

Рис. 2. Зависимости фазы отраженного излучения $(a)$ и интенсивности $(b)$ на частоте $13 \mathrm{GHz}$ от времени выдержки блока льда. В точке $A$ (по шкале времени) температура поверхностного слоя льда составляла $-5^{\circ} \mathrm{C}$, она плавно возрастала до $0^{\circ} \mathrm{C}$ в точке $B$; от точки $B$ до точки $D$ температура не изменялась в этой области. Размеры блока уменьшились из-за его таяния. 


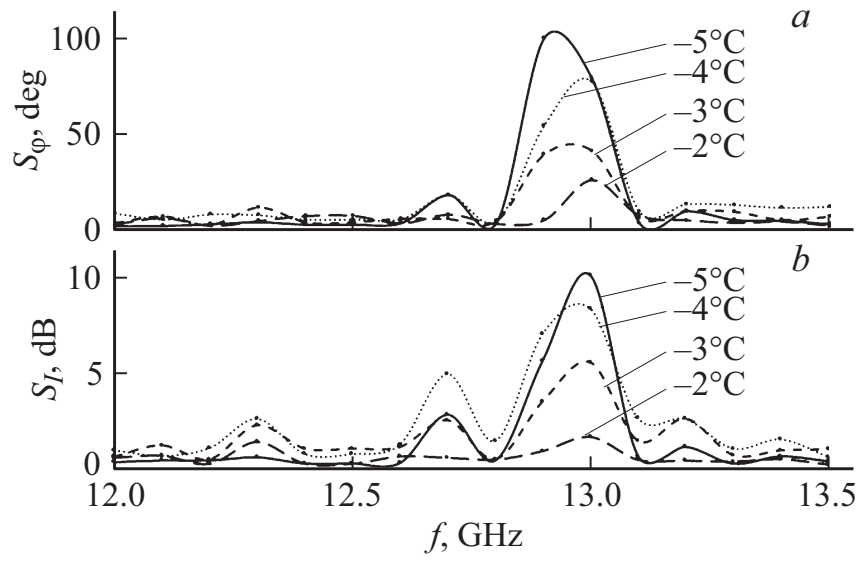

Рис. 3. Зависимости значений стандартного отклонения фазы $(a)$ и интенсивности $(b)$ от частоты при различных температурах льда.

В выполненном эксперименте была обнаружена выраженная селективность флуктуаций характеристик отраженного сигнала в зависимости от частоты при нагревании блока льда до $0^{\circ} \mathrm{C}$. Флуктуации существенно отличались от гауссовских. Эксперимент показал, что на частоте $13 \mathrm{GHz}$ (длина волны излучения во льду $1.35 \mathrm{~cm}$ ) и в полосе частот $\sim 0.3 \mathrm{GHz}$ наблюдается аномалия характеристик отраженного излучения от блока льда при его пластической деформации, вызванной нагреванием и градиентом температуры. Этот эффект обнаружен приблизительно для половины измеренных точек в области частот, для которых наблюдалось возрастание флуктуаций интенсивности отраженного монохроматического излучения и его фазы. При этом фаза отраженной волны могла принимать любое значение в диапазоне $\pm 180^{\circ}$ в некоторые интервалы времени в процессе измерения вблизи $13 \mathrm{GHz}$. Поведение флуктуаций амплитуды на этой частоте было следующим. При уровне отраженного сигнала $\sim-50 \mathrm{~dB}$ наблюдалась асимметрия приращений, при которой сигнал в основном возрастал от 0 до $+20 \mathrm{~dB}$.

Такое поведение микроволновых характеристик можно объяснить возникновением в поликристаллическом образце импульсов рассеянного излучения при хаотическом распределении в объеме блока льда возникающих рассеивателей. Поскольку сильное рассеяние исчезало при достижении температуры $0^{\circ} \mathrm{C}$, когда механизм пластичности изменялся и деформация блока происходила из-за скольжения по прослойкам воды (а не по базисным плоскостям кристаллов), обратное рассеяние микроволнового излучения естественно связать с пластической деформацией кристаллов льда. При течении области среды представляют собой чередующиеся пассивные и активные слои. Данная структура с точки зрения электродинамики соответствует возникновению в объеме образца дифракционных решеток, которые рассевают внешнее излучение. Из-за их нестационарности интенсивность рассеяния и фаза рассеянного излучения испытывают флуктуации. В соответствии с результатами работ $[3,4]$ период решетки из автоволн пластичности составляет $\sim 1 \mathrm{~cm}$. С другой стороны, выявленные длины волн микроволнового излучения с аномальным рассеянием имели характерные значения в интервале $1.23-1.4 \mathrm{~cm}$. Это соответствие, по нашему мнению, подтверждает существование волн течения.

Использованная микроволновая методика измерения характеристик коэффициента отражения позволяет более детально изучать стадии процесса формирования автоволн в объеме поликристаллических образцов на примере пресного льда. Кроме того, изучение льда и мерзлых дисперсных сред новым способом представляет особый интерес ввиду их широкого распространения в природной среде и в разнообразных искусственных объектах.

\section{Список литературы}

[1] Бордонский Г.С., Гурулев А.А., Крылов С.Д. // Письма в ЖТФ. 2009. Т. 35. В. 22. С. 46-54.

[2] Бордонский Г.С. // ЖТФ. 2016. Т. 86. В. 8. С. 131-136.

[3] Зуев Л.Б., Данилов В.И., Баранникова С.А. Физика макролокализации пластического течения. Новосибирск: Наука, 2008. $328 \mathrm{c}$.

[4] Зуев Л.Б. // Успехи физики металлов. 2015. Т. 16. № 1. C. $35-60$.

[5] Шарков Е.А. Радиотепловое дистанционное зондирование Земли: физические основы. М.: ИКИ РАН, 2014. Т. 1. 544 с.

[6] Petrenko V., Whitworth R. Physics of ice. Oxford Univ. Press, 1999. $347 \mathrm{p}$. 